\title{
Direct Oral Anticoagulants in the Real World: Insights into Canadian Health Care Providers' Understanding of Medication Dosing and Use
}

Siavash Piran MD MSc, Sam Schulman MD PhD, Mary Salib MD, Jennifer Delaney RN, Mohamed Panju MD MSc, Menaka Pai MD MSc

\begin{abstract}
About the Authors
Siavash Piran is a clinical scholar at the Division of Hematology and Thromboembolism at McMaster University. Sam Schulman is a professor in the Division of Hematology and Thromboembolism at McMaster University. Mary Salib is a hematologist at St. Catherine's General Hospital. Jennifer Delaney is a registered nurse with the Thrombosis Program at Hamilton General hospital. Mohamed Panju is an associate professor in the Department of General Internal Medicine at McMaster University. Menaka Pai is an associate professor in the Division of Hematology and Thromboembolism at McMaster University. Correspondence may be directed to: mpai@mcmaster.ca Corresponding Author: mpai@mcmaster.ca
\end{abstract}

Submitted: April 19, 2017. Accepted: June 15, 2017. November 7, 2017.

\begin{abstract}
Background: Direct-acting oral anticoagulant (DOAC) use is increasing in Canada. This study evaluated nurse, staff physician, and resident physician understanding of DOAC dosing and administration.
\end{abstract}

Methods: An electronic survey was distributed to health care providers (HCPs) at a hospital in Ontario, Canada. The questions discussed oral anticoagulant indications, dose adjustments, storage and administration, and counselling.

Results: A total of 52 responses were received: 3 from nurses, 1 from a nurse practitioner, 21 from staff physicians (Hematology, Thrombosis Medicine, General Internal Medicine, Neurology), 25 from resident physicians, and 2 unspecified respondents. Twenty-four respondents (46\%) felt comfortable or very comfortable prescribing DOACs. Only 15 (29\%) knew that dabigatran should not be exposed to moisture and $13(25 \%)$ knew that higher doses of rivaroxaban should be taken with food.

Conclusion: HCP understanding of DOACs is variable. Though they express comfort with DOACs, their self-reported knowledge of dosing, administration, and patient counselling is incomplete.

\section{Résumé}

Contexte: L'utilisation d'anticoagulants oraux directs (AOD) est en hausse au Canada. La présente étude évalue la connaissance qu'ont les infirmières et les médecins (membres du personnel et résidents) de l'administration et du dosage des AOD.

Méthodologie: Un sondage en ligne a été effectué auprès des fournisseurs de soins de santé (FSS) d'un hôpital en Ontario, Canada. Les questions portaient sur les indications, l'adaptation posologique, l'entreposage et l'administration des anticoagulants oraux, ainsi que la démarche de conseil au patient.

Résultats: Les 52 répondants se répartissent ainsi : 3 infirmières; 1 infirmière praticienne; 25 médecins membres du personnel (hématologie, thrombose, médecine interne générale et neurologie); 25 médecins résidents. Deux répondants n’ont pas précisé leur statut. Vingt-quatre répondants $(46 \%)$ se sentent à l'aise ou très à l'aise de prescrire des AOD. Seulement 15 répondants 
(29\%) savaient que le dabigatran ne doit pas être exposé à l'humidité et 13 (25\%) savaient que les doses plus élevées de rivaroxaban devaient être prises avec de la nourriture.

Conclusions: La connaissance qu'ont les FSS des AOD est variable. Les FSS se disent à l'aise de travailler avec les AOD, mais, d'après ce qu'ils rapportent, leur savoir en matière de dosage, d'administration et de conseil au patient comporte des lacunes.

In recent years, an increasing number of direct oral anticoagulants (DOACs) have become available. DOACs appear to be effective, safe, and convenient alternatives to warfarin. ${ }^{1-8}$ The 4 available DOACs in Canada are dabigatran, apixaban, rivaroxaban, and edoxaban and are approved by Health Canada for the prevention of stroke and systemic embolism in patients with atrial fibrillation and for treatment and secondary prevention of venous thromboembolism (VTE).

DOACs come with specific recommendations for storage and administration. Dabigatran should not be exposed to moisture as this results in its breakdown and loss of potency. ${ }^{9,10}$ Moreover, dabigatran should be taken as a whole capsule, and not crushed or chewed. Modifying the capsule can lead to increased absorption and potentially increased risk of bleeding. ${ }^{9}$ Rivaroxaban at higher doses should be administered with food. ${ }^{10}$ If it is taken when fasting, its bioavailability is reduced by one third, thereby resulting in potentially increased risk of thrombosis. ${ }^{11}$

Given that laboratory monitoring of DOACs is not routinely performed, it is crucial to ensure that these medications are administrated according to manufacturer's recommendations. It is unclear whether DOACs are appropriately prescribed for indications currently approved by Health Canada, and whether patients are advised on optimal administration. Ideally, HCPs should counsel patients about appropriate DOAC use, however their understanding of this issue is unknown. To determine the level of understanding of administration and indications for DOACs, we conducted a cross-sectional study of HCPs at a Canadian hospital using a survey questionnaire.

\section{Methods}

\section{Study Population}

An electronic questionnaire examining HCP understanding of oral anticoagulant indications, dosing, administration, storage was distributed to physicians in different specialties, nurses, and nurse practitioners. The physician groups included: hematologists, thrombosis specialists, neurologists, internists, and resident physicians.

\section{Data Collection}

The electronic questionnaire was sent via email. Data collected included demographics, understanding of oral anticoagulant:
(1) indications; (2) dosing and dose-adjustment based on renal function and age; (3) storage; and (4) administration. Additional data was collected about how HCPs counsel patients and how often they prescribe oral anticoagulants. Questionnaires were completed anonymously and no identifying data was collected outside of the participant's occupation. Participation in this survey was voluntary. This study was approved by the Hamilton Integrated Research Ethics Board.

\section{Statistical Analysis}

Descriptive statistics was used to identify the proportion of HCPs with understanding of appropriate oral anticoagulant indication, dosing, and dose-adjustment based on age and renal function. HCPs' comfort level with prescribing oral anticoagulants, and the frequency with which they prescribe oral anticoagulants, was also assessed using descriptive statistics.

\section{Results}

\section{Participant Characteristics}

The survey was sent to 300 potential respondents and 52 responses were received: 3 from nurses, 1 from a nurse practitioner, 21 from staff physicians, 25 from resident physicians, and 2 did not specify their profession. The speciality of the staff physicians included: 10 General Internal Medicine; 5 Neurology; 5 Thrombosis; and 1 Hematology. Twenty-two of the 25 residents were from Internal Medicine and 3 were from Neurology. Respondents had a mean of 11.8 years of experience and median of 5.5 years of experience in their field, respectively.

\section{HCPs' Knowledge Base about Oral Anticoagulants}

Only $10 \%$ of the respondents correctly identified the approved indications for all 3 DOACs available in Canada. Only 15 (29\%) knew that dabigatran should not be exposed to moisture and 27 (52\%) knew that it should not be crushed. Thirteen participants (25\%) knew that higher doses of rivaroxaban should be taken with food. Forty-three of the participants (83\%), 38 (73\%), and $42(81 \%)$ adjusted the dose of dabigatran, rivaroxaban, and apixaban, respectively, for renal function. However, only $38(73 \%)$ calculated renal function using the widely accepted Cockcroft-Gault formula. The rest used a laboratory reported e-glomerular filtration rate or creatinine alone. Thirty-one of the 
respondents (60\%) and $29(56 \%)$ adjusted the dose of dabigatran and apixaban, respectively, for age. Additional questions and respondents' answers regarding dose adjustments are listed in Table 1.

Table 1. Questions and Respondent's Answers Regarding Which Drug(s) Can Be Safety Administered Based on the Renal Function and Age

\begin{tabular}{|c|c|c|}
\hline Oral Anticoagulant & Number & $\%$ \\
\hline \multicolumn{3}{|c|}{ Renal Function: $\mathrm{CrCl}$ 30-50 mL/min } \\
\hline Warfarin & 48 & 92 \\
\hline Dabigatran 150 mg BID & 11 & 21 \\
\hline Dabigatran 110 mg BID & 29 & 56 \\
\hline Rivaroxaban 20 mg OD & 8 & 15 \\
\hline Rivaroxaban 15 mg OD & 36 & 69 \\
\hline Apixaban 5 mg BID & 18 & 35 \\
\hline Apixaban 2.5 mg BID & 37 & 71 \\
\hline \multicolumn{3}{|c|}{ Correct answers: all except rivaroxaban 20 mg OD } \\
\hline \multicolumn{3}{|c|}{ Renal Function: $\mathrm{CrCl} 15-30 \mathrm{~mL} / \mathrm{min}$} \\
\hline Warfarin & 49 & 94 \\
\hline Dabigatran 150 mg BID & 0 & 0 \\
\hline Dabigatran 110 mg BID & 1 & 2 \\
\hline Rivaroxaban 20 mg OD & 0 & 0 \\
\hline Rivaroxaban 15 mg OD & 13 & 25 \\
\hline Apixaban 5 mg BID & 2 & 4 \\
\hline Apixaban 2.5 mg BID & 28 & 54 \\
\hline \multicolumn{3}{|c|}{$\begin{array}{l}\text { Correct answers: warfarin and apixaban } 2.5 \mathrm{mg} \mathrm{BID} \text { up to creatinine } \\
\text { clearance } 25 \mathrm{ml} / \mathrm{min}\end{array}$} \\
\hline \multicolumn{3}{|c|}{ Renal Function: $\mathrm{CrCl}<15 \mathrm{~mL} / \mathrm{min}$} \\
\hline Warfarin & 46 & 88.5 \\
\hline Dabigatran 150 mg BID & 0 & 0 \\
\hline Dabigatran 110 mg BID & 0 & 0 \\
\hline Rivaroxaban 20 mg OD & 0 & 0 \\
\hline Rivaroxaban 15 mg OD & 2 & 4 \\
\hline Apixaban 5 mg BID & 1 & 2 \\
\hline Apixaban 2.5 mg BID & 7 & 13.5 \\
\hline \multicolumn{3}{|c|}{ Correct answer: only warfarin } \\
\hline \multicolumn{3}{|c|}{ Age $>80$ years old } \\
\hline Warfarin & 46 & 88.5 \\
\hline Dabigatran 150 mg BID & 5 & 10 \\
\hline Dabigatran 110 mg BID & 32 & 31.5 \\
\hline Rivaroxaban 20 mg OD & 19 & 36.5 \\
\hline Rivaroxaban 15 mg OD & 29 & 56 \\
\hline Apixaban 5 mg BID & 12 & 23 \\
\hline Apixaban 2.5 mg BID & 41 & 79 \\
\hline
\end{tabular}

$\mathrm{BID}=$ twice daily; $\mathrm{CrCl}=$ creatinine clearance; $\mathrm{OD}$ = once daily
Forty-nine of the respondents (94\%) and 27 (52\%) correctly responded that the International Normalized Ratio (INR) was elevated in patients on warfarin and rivaroxaban, respectively. However, 22 (42\%) and 20 (38\%) incorrectly stated that INR was elevated in patients taking dabigatran and apixaban, respectively. Questions and respondents' answers regarding anticoagulant reversal strategies are listed in Table 2.

Table 2. Questions and Respondent's Answers Regarding which Oral Anticoagulant's Effect Can Be Reversed Using Each Reversal Agent

\begin{tabular}{|c|c|c|}
\hline Oral Anticoagulant & Number & $\%$ \\
\hline \multicolumn{3}{|c|}{ Vitamin $\mathrm{K}$} \\
\hline Warfarin & 51 & 98 \\
\hline Dabigatran & 0 & 0 \\
\hline Rivaroxaban & 0 & 0 \\
\hline Apixaban & 0 & 0 \\
\hline \multicolumn{3}{|l|}{ Correct answer: only warfarin } \\
\hline \multicolumn{3}{|c|}{ FFP } \\
\hline Warfarin & 41 & 79 \\
\hline Dabigatran & 7 & 13.5 \\
\hline Rivaroxaban & 7 & 13.5 \\
\hline Apixaban & 6 & 11.5 \\
\hline \multicolumn{3}{|l|}{ Correct answer: only warfarin } \\
\hline \multicolumn{3}{|c|}{ PCC } \\
\hline Warfarin & 45 & 86.5 \\
\hline Dabigatran & 18 & 35 \\
\hline Rivaroxaban & 20 & 38 \\
\hline Apixaban & 20 & 38 \\
\hline \multicolumn{3}{|c|}{ Correct answers: all except dabigatran (activated PCC more effective) } \\
\hline
\end{tabular}

$\mathrm{FFP}=$ fresh frozen plasma; $\mathrm{PCC}=$ prothrombin complex concentrate.

\section{HCPs' Comfort Level, Counselling, and Prescription Patterns}

Twenty-four of the respondents (46\%) felt comfortable or very comfortable prescribing DOACs. Twenty of the participants (38\%) felt somewhat comfortable, while 5 (10\%) felt very uncomfortable, and $3(6 \%)$ did not specify their comfort level. Discomfort with prescribing DOACs was attributed to challenges with reversal of bleeding (31\%), lack of knowledge about food or drug interactions (25\%), lack of knowledge about appropriate dosing and administration (25\%), lack of knowledge about appropriate indications (17\%), challenges with dosing in the setting of renal impairment (21\%), and bleeding risk (19\%).

When counselling patients around DOACs: 51 (98\%) discussed the indication; 51 (98\%) discussed bleeding; 33 (64\%) discussed medication administration (e.g., frequency, with or without meals); 36 (69\%) discussed drug interactions; 33 (64\%) discussed food interactions; and only discussed ways to improve 
adherence (e.g., use of alarms or calendars). The prescribing pattern of HCPs per month is listed in Table 3.

Table 3. How Often Do HCPs Prescribe Each Oral Anticoagulant Each Month

\begin{tabular}{|l|l|l|l|l|l|l|l|}
\hline Frequency Per Month & \multicolumn{1}{|c|}{ Never } & $<5$ & $5-10$ & $10-20$ & $>20$ & Blank \\
\hline Warfarin & 7 & 13 & 12 & 10 & 5 & 5 \\
\hline Dabigatran & 11 & 27 & 8 & 1 & 0 & 5 \\
\hline Rivaroxaban & 8 & 26 & 7 & 2 & 4 & 5 \\
\hline Apixaban & 9 & 25 & 9 & 3 & 1 & 5 \\
\hline
\end{tabular}

\section{Discussion}

Our study demonstrates that despite HCPs' self-expressed comfort with use of DOACs, their knowledge of oral anticoagulant indications, dosing, administration, and storage is suboptimal. HCPs have a unique opportunity to improve patients' understanding and comfort with medication; it is therefore vital that they have accurate information about oral anticoagulants, and can convey this information effectively to their patients.

There is a lack of consensus and a paucity of data around the effect of patient education around oral anticoagulants. A 2013 systematic review evaluating the impact of supplemental patient education on outcomes did not support patient education as a mechanism to improve outcomes. The systematic review's conclusions were limited by poor quality evidence, and did not include patients on DOACs. ${ }^{12}$ Subsequent studies have shown that greater patient education about warfarin therapy was associated with better overall anticoagulant control, which might be predictive of better outcomes. ${ }^{13-15}$ The TREAT randomized trial compared a theory driven intervention using patient interviews, focus groups, educational booklet, self-monitoring diary, and worksheet with usual care. ${ }^{14}$ It found that the educational intervention significantly improved anticoagulation control in patients taking warfarin, and concluded that improving patient education is essential to improve the efficacy and safety of anticoagulation. ${ }^{14}$ A clusterrandomized trial assessed the impact of patient education on knowledge about treatment; it compared patients who received education consisting of a video, a brochure, and a questionnaire with a control group who only received the brochure. ${ }^{15}$ It found that patient education resulted in markedly improved safetyrelated patient knowledge. ${ }^{15}$

Previous studies have shown similar findings of knowledge gap about oral anticoagulants among HCPs. ${ }^{16,17}$ In a study by Couris et al., HCPs including physicians, pharmacists, and dieticians were surveyed using questions about drug and dietary interactions with warfarin. ${ }^{16}$ The authors concluded that additional training and improved knowledge base about drug-dietary interactions among HCPs are crucial to provide adequate patient counselling and possibly optimized clinical outcomes. ${ }^{16}$ Ferguson et al. utilized a paper-based survey distributed during a cardiovascular meeting to assess nurses' knowledge about warfarin-drug interactions and advise on warfarin dietary interactions, administration, monitoring, and duration of anticoagulation. ${ }^{17}$ They found that there was very poor knowledge about warfarin anticoagulation among nurses. ${ }^{17}$

Several "real-world" studies have examined the safety and efficacy of DOACs in patients with atrial fibrillation. ${ }^{18-22}$ Singlearm observational studies examining the real-world use of rivaroxaban in patients with atrial fibrillation ${ }^{20,21,24,25}$ and a 2017 systematic review ${ }^{26}$ confirmed the safety and efficacy outcomes observed in the ROCKET AF. ${ }^{7}$ However dabigatran appears to perform differently outside of the randomized controlled trial setting. A 2016 systematic review of 7 post-marketing observational studies, which included 34,8750 patients with atrial fibrillation taking dabigatran, found that dabigatran at either dose showed no benefit over warfarin in prevention of stroke.23 This finding differs from data reported by the RELY trial, which demonstrated that compared with warfarin, higher dose dabigatran significantly reduced the risk of stroke and systemic embolism. ${ }^{6}$ This raises the possibility that inappropriate use of dabigatran in clinical practice is contributing to its loss of clinical efficacy. Observational studies ${ }^{22,27}$ and a 2017 systematic review $^{28}$ examining the real-world use of apixaban in patients with atrial fibrillation confirmed the safety and efficacy outcomes observed in the ARISTOTLE. ${ }^{8}$

Our study has some limitations. First, there is a potential for selection bias as we surveyed HCPs at one hospital on a volunteer basis and had a low response rate. The knowledge base of responders may have been different from that of nonresponders. Five of the respondents were experts in thrombosis; HCPs' knowledge might be more subpar if sampling is performed at a centre with no thrombosis expertise. A national study is needed to get a more accurate picture of Canadian practitioners' understanding of DOACs. However, our study provides an initial look into an area where quality improvement appears to be badly needed. Second, due to its small sample size, our study could not compare the groups demonstrating appropriate understanding relative to those that did not. A larger study may yield information on the impact of specialty and years in practice. Third, as with any cross-sectional study, our study only offers a snapshot of the current practice. Nonetheless, our study is the first of its kind to describe HCPs' knowledge of DOAC indications and administration, and paves the way for future studies examining the impact of educational programs on medication literacy.

\section{Conclusions}

Though HCPs express comfort with prescribing DOACs, our study raises concerns around their self-reported knowledge of DOACs use. DOACs are a widely prescribed class of drugs, which can cause serious side effects if not prescribed and 
taken correctly. It is essential that HCPs provide patients with accurate information and counselling around DOACs, in order to optimize safe and efficacious use. Future studies should focus on educational strategies to improve HCPs' knowledge base in this area, and associations between medication literacy and the safety and efficacy of DOACs.

\section{Funding}

SP is a recipient of a CanVECTOR thrombosis fellowship.

\section{References}

1. Schulman S, Kearon C, Kakkar AK, et al. RE-COVER Study Group. Dabigatran versus warfarin in the treatment of acute venous thromboembolism. N Engl J Med 2009;361:2342-52.

2. EINSTEIN Investigators. Oral rivaroxaban for symptomatic venous thromboembolism. N Engl J Med 2010;363:2499-510.

3. EINSTEIN-PE Investigators. Oral rivaroxaban for the treatment of symptomatic pulmonary embolism. N Engl J Med 2012;366:1287-97.

4. Agnelli G, Buller HR, Cohen A, et al. AMPLIFY Investigators. Oral apixaban for the treatment of acute venous thromboembolism. N Engl J Med 2013;369:799-808.

5. Hokusai-VTE Investigators. Edoxaban versus warfarin for the treatment of symptomatic venous thromboembolism. N Engl J Med 2013;369:1406-15.

6. Connolly SJ, Ezekowitz MD, Yusuf S, et al. Dabigatran versus warfarin in patients with atrial fibrillation. N Engl J Med. 2009;361:1139-51.

7. Patel MR, Mahaffey KW, Garg J, et al. Rivaroxaban versus warfarin in nonvalvular atrial fibrillation. N Engl J Med. 2011;365(10):883-91.

8. Granger CB, Alexander JH, McMurray JJ, et al. Apixaban versus warfarin in patients with atrial fibrillation. N Engl J Med. 2011;365(11):981-92.

9. Pradaxa (Dabigatran Etexilate Mesylate) prescribing information. Rigefield, CT: Boehringer Ingelhiem Pharmaceuticals; 2015.

10. FDA Drug Safety Communication: Special storage and handling requirements must be followed for Pradaxa (dabigatran etexilate mesylate) capsules. Safety announcement: http://www.fda.gov/Drugs/DrugSafety/ ucm248746.htm.

11. Xarelto (Rivaroxaban) prescribing information. Titusville, NJ: Janssen Pharmaceuticals; 2016.

12. Wong PY, Schulman S, Woodworth S, Holbrook A. Supplemental patient education for patients taking oral anticoagulants: systematic review and meta-analysis. J Thromb Haemost 2013;11(3):491-502.

13. Tang EOYL, Lai CSM, Lee KKC, Wong RSM, Cheng G, Chan TYK. Relationship between patients' warfarin knowledge and anticoagulation control. Ann Pharmacother 2003;37:34-9.

14. Clarkesmith DE, Pattison HM, Lip GY, Lane DA. Educational intervention improves anticoagulation control in atrial fibrillation patients: the TREAT randomized trial. PLoS One 2013;8(9):e74037.
15. Vormfelde SV, Abu Abed M, Hua TD, Schneider S, Friede T, Chenot JF. Educating orally anticoagulated patients in drug safety: a cluster-randomized study in general practice. Dtsch Arztebl Int 2014;111(37):607-14.

16. Couris RR, Tataronis GR, Dallal GE, Blumberg JB, Dwyer JT. Assessment of healthcare professionals' knowledge about warfarin-vitamin K drug-nutrient interactions. J Am Coll Nutr 2000;19(4):439-45.

17. Ferguson C, Inglis SC, Newton PJ, Middleton S, Macdonald PS, Davidson PM. Education and practice gaps on atrial fibrillation and anticoagulation: a survey of cardiovascular nurses. BMC Med Educ 2016;16:9.

18. Graham DJ, Reichman ME, Wernecke M, et al. Cardiovascular, bleeding, and mortality risks in elderly Medicare patients treated with dabigatran or warfarin for nonvalvular atrial fibrillation. Circulation 2015;131(2):157-64.

19. Larsen TB, Rasmussen LH, Skjøth F, Due KM, Callréus T, Rosenzweig M, Lip GY. Efficacy and safety of dabigatran etexilate and warfarin in "real-world" patients with atrial fibrillation: a prospective nationwide cohort study. J Am Coll Cardiol 2013;61(22):2264-73.

20. Tamayo S, Frank Peacock W, Patel M, et al. Characterizing major bleeding in patients with nonvalvular atrial fibrillation: a pharmacovigilance study of 27 467 patients taking rivaroxaban. Clin Cardiol 2015;38:63-68.

21. Peacock WF, Patel M, Tamayo S, Sicignano N, Hopf K, Yuan Z. Major bleeding in a post-marketing assessment of 39,052 nonvalvular atrial fibrillation patients on rivaroxaban. Eur Heart J 2015;36:687.

22. Lip GY, Keshishian A, Kamble S, Pan X, Mardekian J, Horblyuk R, Hamilton M. Real-world comparison of major bleeding risk among non-valvular atrial fibrillation patients initiated on apixaban, dabigatran, rivaroxaban, or warfarin. A propensity score matched analysis. Thromb Haemost 2016;116(5):975-86.

23. Romanelli RJ, Nolting L, Dolginsky M, Kym E, Orrico KB. Dabigatran versus warfarin for atrial fibrillation in real-worldclinical practice: a systematic review and meta-analysis. Circ Cardiovasc Qual Outcomes 2016;9(2):126-34.

24. Beyer-Westendorf J, Förster K, Pannach S, et al. Rates, management, and outcome of rivaroxaban bleeding in daily care: results from the Dresden NOAC registry. Blood 2014;124:955-62.

25. Camm A, Amarenco P, Haas S, et al. XANTUS: a real-world, prospective, observational study of patients treated with rivaroxaban for stroke prevention in atrial fibrillation. Eur Heart J 2015;37:1145-53.

26. Bai Y, Deng H, Shantsila A, Lip GY. rivaroxaban versus dabigatran or warfarin in real-world studies of stroke prevention in atrial fibrillation: systematic review and meta-analysis. Stroke 2017;48(4):970-76.

27. Yao X, Abraham NS, Sangaralingham LR, et al. Effectiveness and safety of dabigatran, rivaroxaban, and apixaban versus warfarin in non-valvular atrial fibrillation. J Am Heart Assoc 2016;5(6):e003725.

28. Li X, Deitelzweig S, Keshishian A, et al. Effectiveness and safety of apixaban versus warfarin in non-valvular atrial fibrillation patients in "real-world" clinical practice. A propensity-matched analysis of 76,940 patients. Thromb Haemost 2017 Mar 16. doi: 10.1160/TH17-01-0068. [Epub ahead of print]. 